\title{
An Identification of the Predominance Factors of Sustainable Manufacturing Industry Competitiveness
}

\author{
Ni Luh Putu Hariastuti ${ }^{1}$, Pratikto ${ }^{2}$ \\ Department of Mechanical Engineering \\ Brawijaya University \\ Malang, Indonesia \\ ${ }^{1}$ putu_hrs@yahoo.com, ${ }^{2}$ prayone_adi@yahoo.com
}

\author{
${ }^{3}$ Purnomo Budi Santoso, ${ }^{4}$ Ishardita Pambudi Tama \\ Department of Industrial Engineering \\ Brawijaya University \\ Malang, Indonesia \\ 33psabn@yahoo.com, ${ }^{4}$ kangdith@ub.ac.id
}

\begin{abstract}
Small and Medium Industry (SMI) is an industry that drives national economic growth in Indonesia. Its existence makes it as the main industry supporting the activity of manufacturing industries globally. Since the existence of SMIs for the nation's economy is important, it is necessary to make an effort to increase the predominance of competitiveness in facing the competition. This research aims to identify the factors that may improve the predominance of manufacturing industry competitiveness through sustainable manufacturing aspects. Through analysis of strengths, weaknesses, opportunities and threats (SWOT analysis) and evaluation of cause and effect diagrams, the factors that influence the predominance of industrial competitiveness can be determined. The study results showed that aspects of sustainable manufacturing through value creation factors, namely products, equipment, production processes, organization and human resources that involving the partnership process in it, are able to contribute to minimizing the constraint factors that cause the low competitiveness of the manufacturing industry. The main constraints to the low competitiveness of the manufacturing industry are product quality, capitalization, technology, human resources and markets.
\end{abstract}

Keywords-manufacturing industry; sustainable manufacturing; sustainable value creation; partnership.

\section{INTRODUCTION}

The free market in Indonesia as the effect of ASEAN Economic Society 2015 makes every party directly engaged in the business activities, especially Small and Medium Industries (SMIs), need to have adequate business dynamism and competitiveness. Industrial competitiveness obviously needs to be supported by sustainable manufacturing activities demanding for improvement process in each manufacturing system starting from the development strategy design phase to the final phase of the product itself [1]. Sustainable manufacturing concepts can be applied in designing strategies to increase the advantages of industrial competitiveness [2]. This concept refers to three sustainability aspects known as the triple bottom line, namely three aspects of sustainable manufacturing that involve economic, social, and environmental aspects [3], [4]. This shows that the sustainability process engaging all manufacturing aspects, thoroughly integrated in every manufacturing activity in producing products [5]. Improvement in the predominance of competitiveness by engaging sustainable manufacturing may become one of SMIs' keys to success in facing the rivalry.

The existence of Small and Medium Industries (SMIs), especially in Indonesia, has a very vital and strategic role in economic development and growth. The growth of SMIs is a source of employment. However, the previous studies showed that the performance of Small and Medium Industries is relatively low, not only compared to large businesses, but also compared to SMIs in developed countries [6], [7]. Moreover, imported products which increasingly flood the free market makes the small business actors must try hard to survive. SMIs' weaknesses in terms of financing, technology use, product innovation, efficiency and market research are the major obstacles for SMI to be able to compete with large businesses [8], [9].

All this time, the discussion regarding the predominance of industry competitiveness is still limited to the achievement on economic excellence in this case an increase in profit obtained by the industry in their business activities [8], [10]. The limited number of discussion on the predominance of competitiveness that involves sustainability aspects that refer not only to economic aspect, but also involve environmental and social aspects which are sustainability aspects of triple bottom line manufacturing. Considering this gap, this research tried to involve those three sustainability aspects of triple bottom line manufacturing in designing the strategy to improve the expected competitiveness. This research aims (1) to identify the linkages between the factors of sustainable value creation and the increase of industrial competitiveness, (2) to determine sustainable manufacturing factors that may affect the increase of competitiveness in the manufacturing industry. The object of this research was limited to the SMI processing metal (NGINGAS) in East Java.

\section{Methodology}

\section{A. Manufacturing Industry Competitiveness.}

The growth and success of a manufacturing industry is greatly influenced by the development of economic, political, social and cultural technology, as well as environmental aspects that is constantly changing. In addition, the achievement of industrial competitiveness is basically capable 
to be an indicator of predominance improvement for a country's global competitiveness [10]. The development of SMIs as the supporting industry of national economy, with economic globalization, has resulted in the emergence of new competitors. This requires SMIs to always strive to improve their competitiveness through sustainable innovation. The strategy of SMIs in facing global competition requires them to be more innovative in terms of information technology use, more flexible expertise, increasing market through collaboration with larger companies, and determining more specific target markets [9]. Through the predominance of competitiveness, it is expected that SMIs can survive in the competition globalization current.

\section{B. Sustainable Manufacturing Value Creation.}

Sustainable manufacturing is the production of manufacturing products through economic process that reduces negative environmental impacts while contributing to preserve energy and natural resources. Sustainable manufacturing also safeguards the safety of employees, communities, and consumers including developing sustainable designs [4]. The measurement of sustainability performance is always based on the triple bottom line focusing on the environment, economy, and social. A company is said to have sustainable manufacturing system when the company has been able to achieve sustainability level in all three aspects. The implementation of sustainable manufacturing in industry does not only require production system planning based on the three sustainability pillars, but also a holistic method of implementation to support continuous improvement concept [3]. In its implementation, sustainable manufacturing activities are able to create sustainable value through five factors of value creation which are thoroughly integrated both vertically and horizontally in the production activities [11]. Those five creation factors are product, production process, equipment's, organization and human resources involved in sustainable manufacturing activities.

\section{RESULT AND DISCUSSION}

The opening of free market demands that small industries in Indonesia be able to compete globally since the imported products flooded the local markets. From the results of the survey conducted on Ngigas SMIs, it was found that the existing condition could be explained based on the strengths, weaknesses, opportunities, and threats in facing the competition. This condition showed that there were quite a number of weaknesses in SMI indicating the low competitiveness they have.
Table I. Existing Condition of Manufacturing SMIs

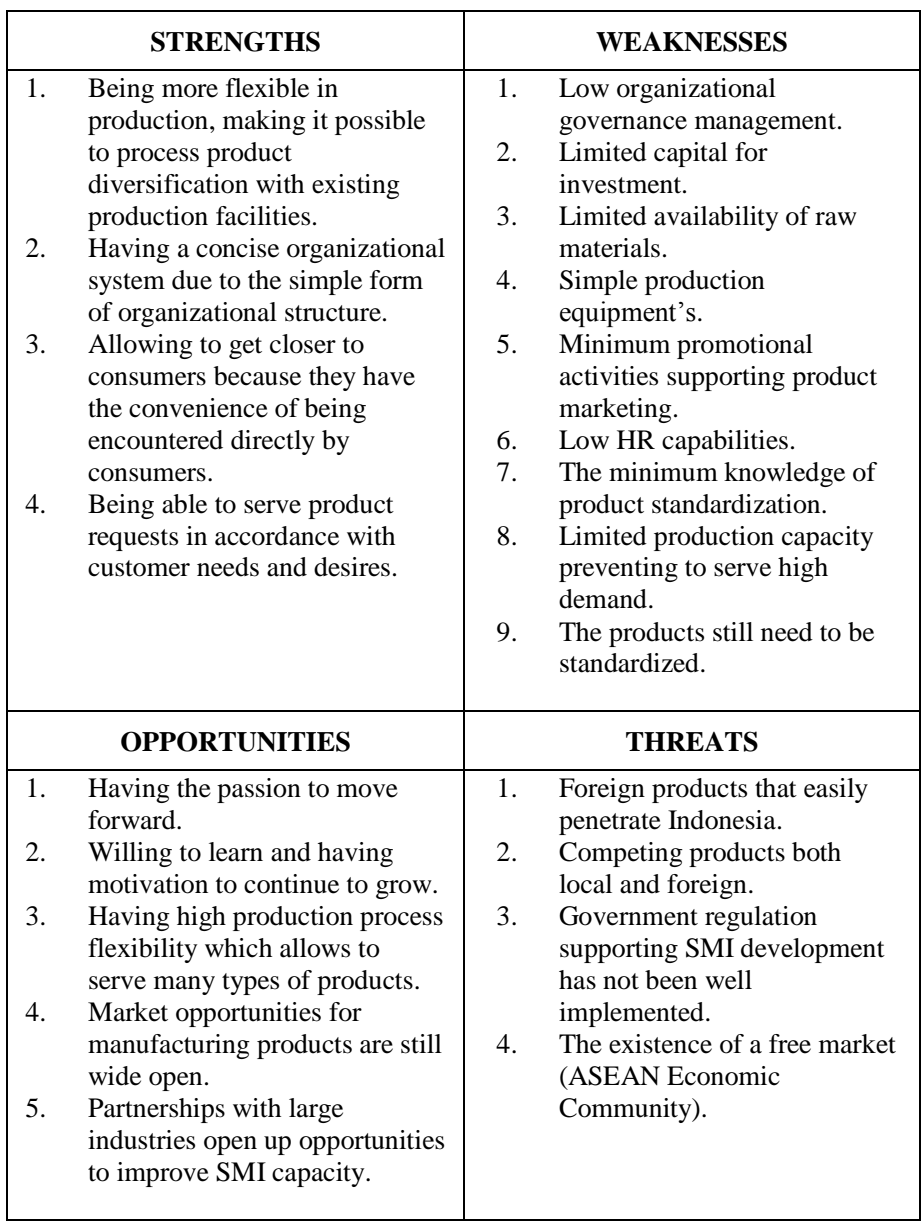

Based on the explanation about the strengths, obstacles, and opportunities faced by SMIs, cause and effect diagram can be drawn to clarify the variables causing low SMI competitiveness. The following is a causal diagram explaining the factors causing low competitiveness of manufacturing SMI. 


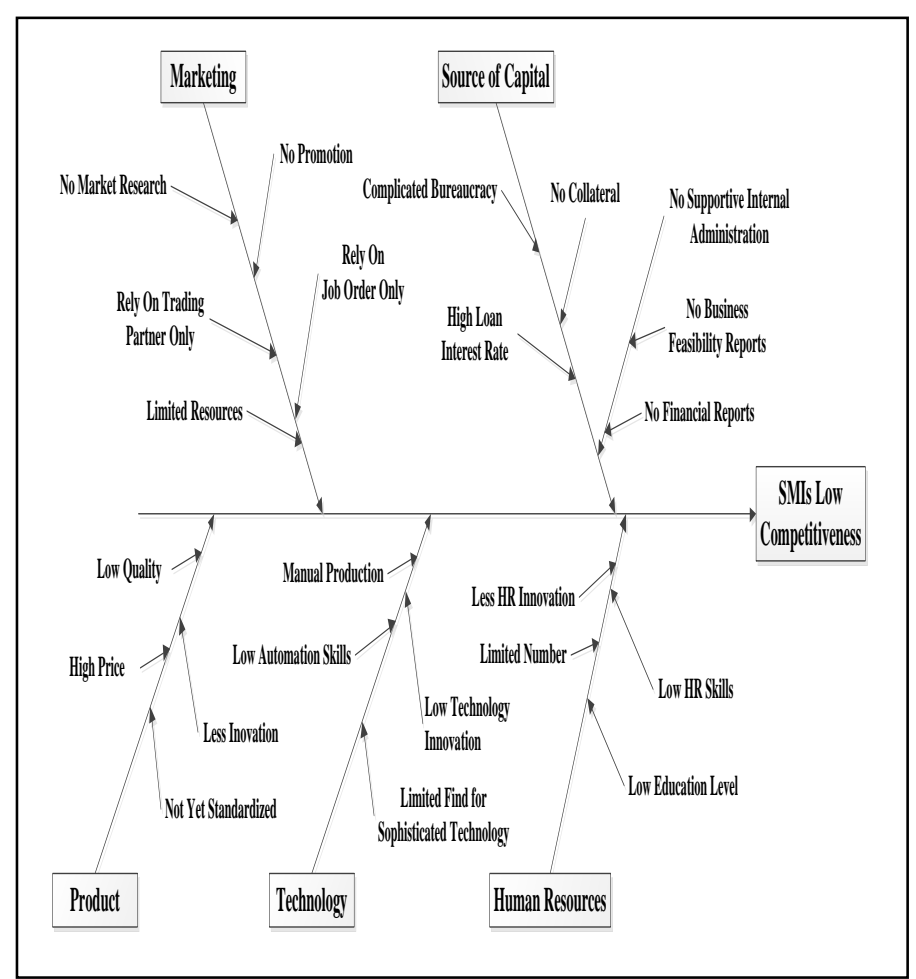

Fig. 1. Causal Diagram of Low SMI Competitiveness

From the causal diagram, it can be seen that there are five main factors causing the low SMI competitiveness. Those factors are capital, marketing, technology, and human resources which basically influence each other in creating innovation that support competitive predominance.

Competitiveness became a force to face competition in which comparative predominance as the main goal that needs to be prioritized by manufacturing industry. It was expected that manufacturing industry did not only focus on economic issues, but also on the impact of production on environmental and social aspects in carrying out sustainable production system. The benefits and additional values of the output should be experienced by consumers and all parties involved [12]. The value creation process was the key to the implementation of sustainable manufacturing system. This process involved five main factors that can produce additional values in the production process. Those five main factors are product, process, equipment's, organization, and human resources. It showed that the value creation of manufacturing system did not only involve production floor as vertical integration, but also horizontal integration involving all stakeholders from the supply chain in fulfilling raw materials to how the product safely and comfortably reaches the consumers [11]. The existence of value creation system in manufacturing activity may give positive effects in the decision making process. Value creation is the basis for increasing industrial competitiveness in facing competition.

On the other hand, increasing national economy competitiveness in facing global competition involved all actors in the existing economic life. Real efforts were needed in creating a climate which is able to stimulate the establishment of strong business partnerships among all economic actors. The key to SMI success in the competition in both domestic and global market is to build partnership with large companies [9]. It was proven that one of the factors driving the economy of Asian countries such as China, Japan, and Korea Is the triple helix partnership which is a synergy between SMIs and government, as well as private sectors and universities in realizing support for industrial development through policy, technology transfer, and ready-to-use technology updates which can optimize the performance of rural industries [13].

Partnership is one of solutions to overcome the gap in SMIs and a means of increasing work productivity. Basically, the partnership values can be used for sustainable value creation in an effort to develop and improve SMIs business performance. The following is a causal diagram analysis of increasing competitiveness of manufacturing industry involving partnership and value creation factors previously described.

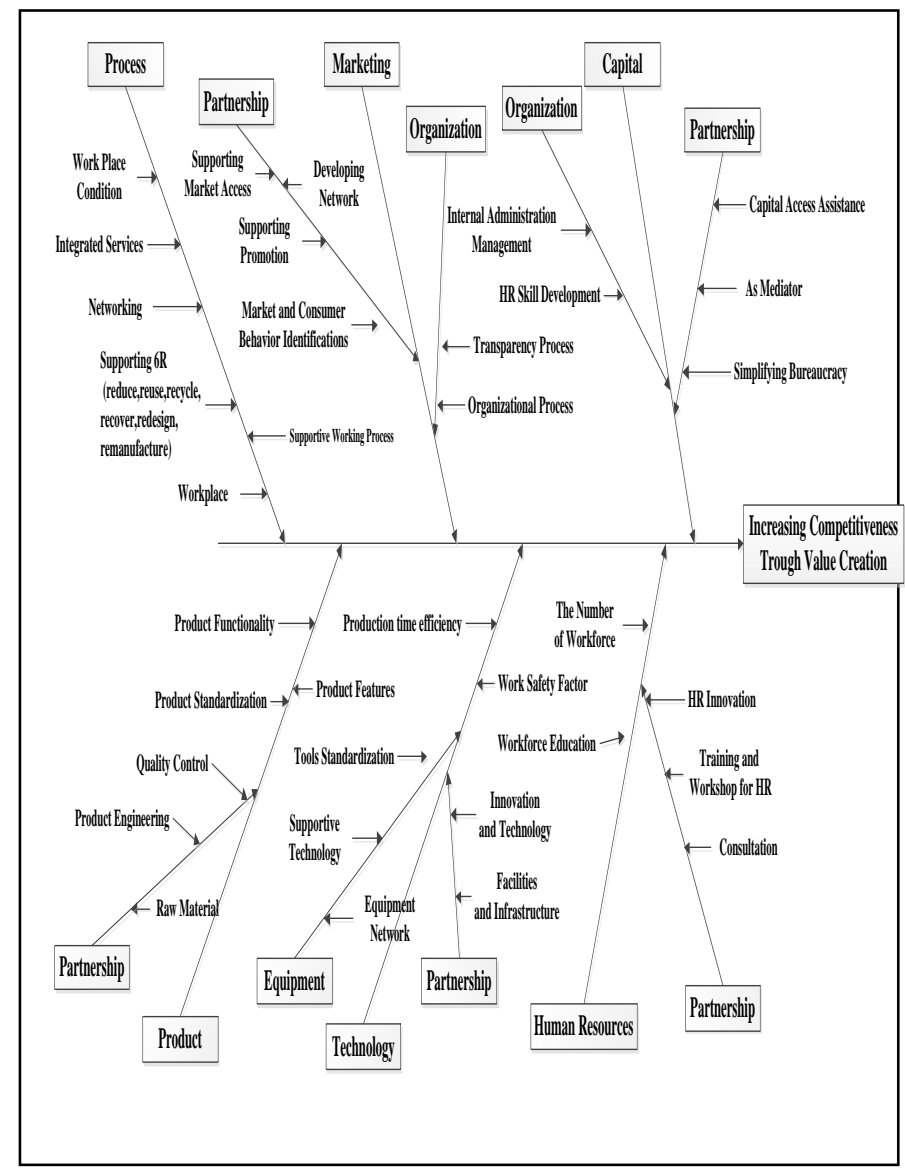

Fig. 2. Causal Diagram of Increasing Competitiveness through Value Creation and Partnership

Figure 2 shows that the concept of sustainable value creation through sustainable value creation through value creation and partnership is able to anticipate the emergence of factors causing low competitiveness of manufacturing industry. The involvement of value creation and partnership factors in an effort to increase industrial competitiveness has 
an important role in every criterion causing SMIs low competitiveness. This shows that the value creation and partnership can be a benchmark in an effort to increase the expected competitiveness. The connection among indicators is presented in figure 3 .

Fig. 3. The connection among indicators of increasing manufacturing

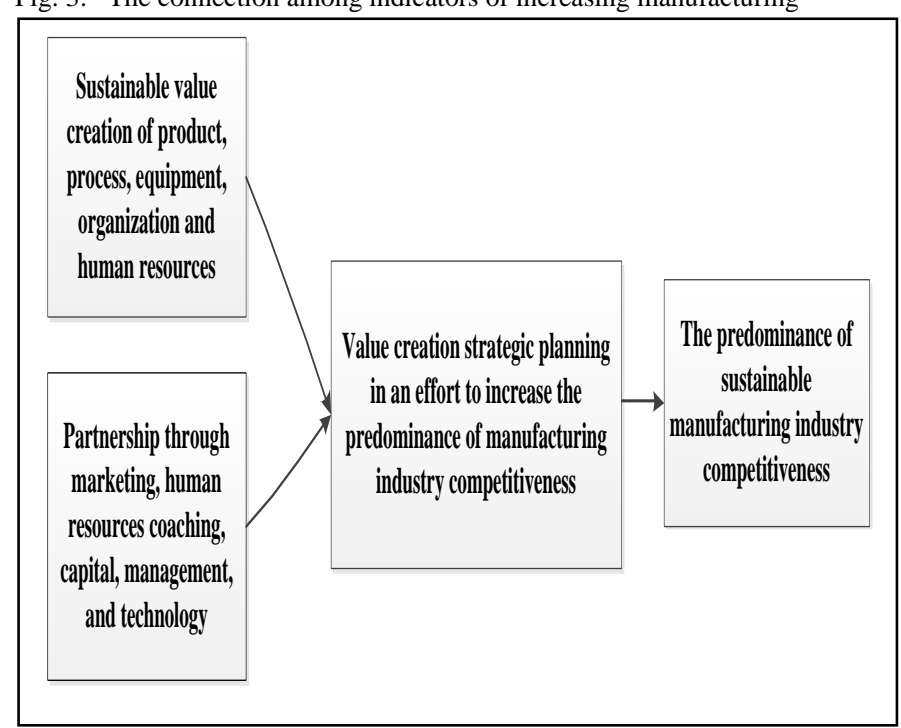

Fig. 4. industry competitiveness

The competitiveness of manufacturing industry as a decision variable is affected by indicators of sustainable value creation including partnership indicator which in its implementation is able to improve the predominance of industrial competitiveness.

\section{CONCLUSION}

Based on the analysis of self-evaluation conducted through the elaboration of strengths, weaknesses, opportunities, and threats faced by metal industry, it can be concluded that efforts to support the improvement of manufacturing industry competitiveness is needed. The analysis results showed that sustainable manufacturing concept was able to become the basis of sustainable value creation process through its factors supported by the implementation of partnership which can minimize the factors causing the low competitiveness of manufacturing industry. Sustainable manufacturing through factors of product, equipment's, production, organization, and human resources as well as supported by partnership concept was able to improve manufacturing industry competitiveness in an effort to face the competition.

\section{ACKNOWLEDGMENT}

This research was supported by LPDP BUDI-DN as a foundation providing research fund for the improvement of Indonesian lecturers. We would like to thank all the parties engaged in supporting this research.

\section{REFERENCES}

[1] I.S. Jawahir, and R. Bradley, "Technological Elements of circular economy and the principles of 6r-based closed-loop material flow in sustainable manufacturing," Procedia CIRP, vol. 40, pp. 103-108, 2016.

[2] S. Singh, E.U. Olugu, and S.N. Musa, "Development of sustainable manufacturing performance evaluation expert system for small and medium enterprises," Procedia CIRP, vol. 40, pp. 609-614, 2016.

[3] B.S. Linke, G.J. Corman, D.A. Dornfeld, and S. Tönissen, "Sustainability indicators for discrete manufacturing processes applied to grinding technology," J. Manuf. Syst., vol. 32, no. 4, pp. 556-563, 2013.

[4] K.R. Haapala, J. Camelio, J.W. Sutherland, S.J. Skerlos, and D.A. Dornfeld, "A review of engineering research in sustainable manufacturing," J. Manuf. Sci. Eng., vol. 135, no. August 2013, pp. 1$16,2016$.

[5] S.M.Y.E. Amrinal, "Key performance indicators for sustainable manufacturing evaluation in automotive companies," Proc. 2011 IEEE IEEM, pp. 1093-1097, 2011.

[6] T. Tambunan, "SME development in indonesia: do economic growth and government supports matter?," 2008.

[7] S.B. Moore and S.L. Manring, "Strategy development in small and medium sized enterprises for sustainability and increased value creation," J. Clean. Prod., vol. 17, no. 2, pp. 276-282, 2009.

[8] T.T.H. Tambunan, "Development of small and medium enterprises in a developing country: The Indonesian case," J. Enterprising Communities, vol. 5, no. 1, pp. 68-82, Mar. 2011.

[9] B. Callan and J. Guinet, "Enhancing the competitiveness of SMEs Workshop 1 enhancing the competitiveness of SMEs," [Online]. Available: http://www.oecd.org/cfe/smes/2010176.pdf. [Accessed: 30Aug-2018].

[10] F. Ülengin, "A decision support methodology to enhance the competitiveness of the Turkish automotive industry," Eur. J. Oper. Res., vol. 234, pp. 789-801, 2014.

[11] P. Bilge, F. Badurdeen, G. Seliger, and I. S. Jawahir, "Model-based approach for assessing value creation to enhance sustainability in manufacturing," Proc. CIRP, vol. 17, pp. 106-111, 2014.

[12] P. Bilge, "Conceptual modelling of interactions among value creation factors for improved sustainable value creation," Int. J. Strateg. Eng. Asset Manag., vol. 2, no. 3, pp. 287-311, 2015.

[13] W. Yuzhu, "Science: china, economic regionalism, and east asian integration," Japanese J. Polit. Sci., vol. 12, no. June 2011, pp. 195-212, 2015 . 